\title{
Population status and sustainability of Yellow-crested cockatoo (Cacatua sulphurea sulphurea) on Pasoso Island, Central Sulawesi, Indonesia
}

\author{
MOH. IHSAN ${ }^{1,2, \vartheta}$, ANI MARDIASTUTI ${ }^{3}$, BURHANUDDIN MASY'UD ${ }^{3}$, YENI A. MULYANI ${ }^{3}$ \\ ${ }^{1}$ Program of Tropical Biodiversity Conservation, Department of Forest Resources, Conservation and Ecotourism, Faculty of Forestry and Environment, \\ Institut Pertanian Bogor. Jl. Ulin LingkarAkademik, Kampus IPB Dramaga, Bogor 16680, West Java, Indonesia. ”email: ihsannurmallo@ gmail.com \\ ${ }^{2}$ Department of Forestry, Faculty of Forestry, Universitas Tadulako. Jl. Soekarno Hatta Km. 9, Kampus Bumi Tadulako, Tondo, Palu 94148, \\ Central Sulawesi, Indonesia \\ ${ }^{3}$ Department of Forest Resources, Conservation and Ecotourism, Faculty of Forestry and Environment, Institut Pertanian Bogor. J1. Ulin Lingkar \\ Akademik, Kampus IPB Dramaga, Bogor 16680, West Java, Indonesia
}

Manuscript received: 31 March 2021. Revision accepted: 22 May 2021.

\begin{abstract}
Ihsan M, Mardiastuti A, Masy'ud B, Mulyani YA. 2021. Population status and sustainability of Yellow-crested cockatoo (Cacatua sulphurea sulphurea) on Pasoso Island, Central Sulawesi, Indonesia. Biodiversitas 22: 3277-3283. Yellow-crested cockatoo (Cacatua sulphurea sulphurea) is a sub-species of Cacatua sulphurea which is spread in Sulawesi and several surrounding islands, including on Pasoso Island. This cockatoo population is under tremendous pressure until categorized as critical. So far, there is no comprehensive information about population status and sustainable population size. The objective of this research area was to assess the current status or size of the population, study the size of the sustainable population and study the determinants factor of the Yellowcrested cockatoo population sustainability on Pasoso Island. The result showed that the population of the Yellow-crested cockatoo in Pasoso Island was only 3 individuals, consists of 2 adults as the parent, and 1 young individual. From 5 analyzed scenarios of the minimum sustainable population size, the 4.1 scenario is the best scenario to maintain the sustainability of the Yellow-crested cockatoo population on Pasoso Island, which is a minimum population size of four pairs ( 8 adult individuals). The determinants of population sustainbility analysis with the minimum sustainable population size ( 8 individuals or 4 pairs of broodstock) showed that inbreeding and predation as determinant factors. These factors need to be controlled through mating management and predator control by both humans and carnivorous animals.
\end{abstract}

Keywords: Cacatua sulphurea sulphurea, inbreeding, Pasoso Island, population, predation, viability

\section{INTRODUCTION}

Yellow-crested cockatoo (Cacatua sulphurea sulphurea) is a sub-species of Cacatua sulphurea, spread on Sulawesi and several surrounding islands, including Pasoso Island. The population of these sub-species is under tremendous pressure, especially due to excessive catching for trade and habitat destruction. So that, it is included in the critical category (Critically endangered) based on the IUCN list (Mallo et al. 2000; Birdlife 2021). The yellowcrested cockatoo has been declared one of the Indonesian government's protected species under the PP. No. 7, 1999 , Ministry of Environment and Forestry Regulation No. P.106/MENLHK/SETJEN/KUM.1/12/2018 and is included in the CITES Appendix I list (CITES 2021).

The population of the Yellow-crested cockatoo was decreased sharply from the 1980s to the 1990s as the other Yellow-crested cockatoo populations on the island of Sulawesi were. The population degradation began to slow down in mid-1992 caused by the population became smaller and the quota for catching Yellow-crested cockatoo was stopped (Mallo et al. 2000; BKSDA 2014).

The population of the Yellow-crested cockatoo on Pasoso Island was relatively fluctuating after the population degradation in the 1980-1990s. In 2000, there were 7-15 individuals (Mallo et al. 2000), in 2012 the population increased by 14-17 individuals (Nandika et al. 2012), and in 2015 the population decreased drastically to 8 individuals (Sandy 2015). Although the main cause of population degradation (catching for trade) has been resolved, intensive protection and monitoring efforts have been carried out, the population of Yellow-crested cockatoo on Pasoso Island still decrease. This condition shows that other factors affect population degradation. Demographic factors are one of the factors that are predicted to affect the population degradation of Yellowcrested cockatoo on Pasoso Island.

The sustainability of wildlife species can be predicted using population viability analysis (PVA). PVA is a method to estimate the threat faced by a population of a species from population degradation or extinction. This method can estimate the population opportunity to recover based on species-specific data and models (Akçakaya and Sjögren-Gulve 2000). It is often used in conservation priorities that focus on populations (Morrison et al. 2016) and also be used to make predictions of a population (Haskins 2015). It helps to assess the extinction risk of endangered species and to identify key factors that affect population status and prospects for sustainability (Zhang and Zheng 2007). The method plays a role in conservation 
theory, policy and management that generally focuses on single species (Pe'er et al. 2013) and is useful in the management of endangered species (Chaudhary and Oli 2019). Despite the advantages compared to other methods, PVA must be supported by adequate long-term data (Zeigler et al. 2013). These data, nowadays, may be difficult to collect (Akçakaya and Sjögren-Gulve 2000). However, Skarpaas and Stabbetorp (2011) suggested that data from scientific collections can be used for PVA analysis. Zhang and Zheng (2007) also mentioned that the results of PVA analysis with limited data are still relevant to be used as a guide for species management and future research.

The current management on Pasoso Island, strongly suspected, not involved demographic factors as the basis for managing the Yellow-crested cockatoo population. Therefore, it is important to conduct research that includes the demographic factors as a factor affecting population degradation and growth as a model to predict the survival possibility of the Yellow-crested cockatoo population on Pasoso Island. With the PVA approach, key factors that affect population survival can be identified and used as a reference in determining appropriate conservation efforts.
Based on this idea, this research aimed to (1) assess the current population status, (2) asses the size of the sustainable population, and (3) examine the determinant keys of the sustainability of the Yellow-crested cockatoo population on Pasoso Island.

\section{MATERIALS AND METHODS}

\section{Study area}

The research was conducted from April to September 2019 at the Pasoso Island Wildlife Reserve, Central Sulawesi, Indonesia. Observations and data measurements were carried out for four types of Yellow-crested cockatoo habitat, which were primary habitat type, ecotonic habitat type, plantation habitat type and dry shrub habitat type (Figure 1). Pasoso Island $\left(0^{0} 4^{\prime} 20^{\prime \prime}-0^{0} 7{ }^{\prime} 20^{\prime} \mathrm{N}\right.$ and $119^{0} 36^{\prime} 20^{\prime \prime}-119^{0} 39^{\prime} 00^{\prime}$ E) has an area of 45 ha, with altitudes ranging from 0-85 meters above sea level (m asl.), rainfall ranges from $41-465 \mathrm{~mm}$, air temperature ranges from 26.1-28.9 ${ }^{\circ} \mathrm{C}$ with an average relative humidity of $76.73 \%$

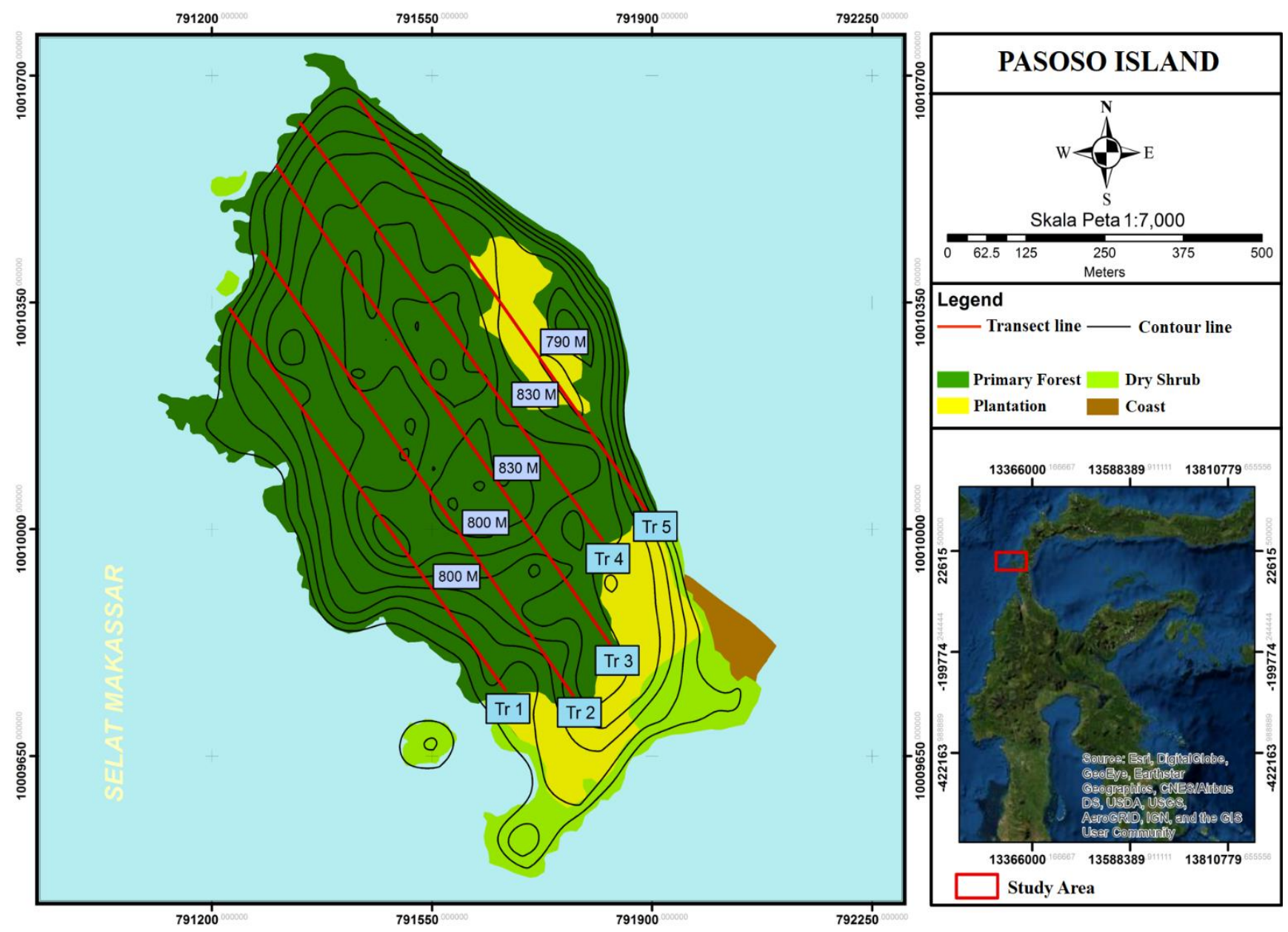

Figure 1. Pasoso Island (Central Sulawesi, Indonesia) and transect exploration of Yellow-crested cockatoo map 


\section{Procedures}

\section{Data of population}

The population data was collected by exploration on all habitat of the Yellow-crested cockatoo on Pasoso Island. The observation was performed by walking on predetermined transect lines. The number of observation transects was 5 parallel lines that were drawn from the Southern part to the Northern part follow the shape of Pasoso with a distance of $40 \mathrm{~m}$ between each transect (Figure 1). Observations were carried out twice every day on the same transect, during the bird's active hours, which were in the morning (05.30-10.00 WITA) and the evening (16.00-18.00 WITA). A team carried out data of population collection on each transect with 2 people: enumerator and backup worker. Every encounter with a yellow-crested cockatoo is carried out by recording the activity observed, the time of the encounter, the length of time of the encounter, the direction of coming and direction of going. Each observation transect was observed 3 days a month and was conducted for three months. Observations of Yellow-crested cockatoo sex were carried out for three days using a Nikon D300i DSLR camera.

\section{Data of sustainable population size and determinant factors of population sustainability}

The scenario designs test determines sustainable population size and determinant factors of population sustainability. To create a scenario design, primary data and secondary data are necessary as input. Primary data is collected from the latest population data using the exploration method. Secondary data is inbreeding pressure, disasters, mating system, reproductive age, maximum reproductive age, number of children in one childbirth, mortality rate, and mate monopolization. Secondary data were collected from various literature or previous research results related to other Yellow-crested cockatoo species, genus or family.

\section{Data for determination analysis of minimum sustainable population size}

Several input parameters were used to determine the minimum sustainable population size that was collected from the literature reference. The basic arguments for determine input parameters are presented below.

\section{Number of iterations, simulation time, the definition of extinction, the total population}

Iteration in the Vortex PVA simulation is relatively unlimited, depending on the goal. An expected overview of the simulation can use 100 iterations. It is recommended to use 500 or even 1000 iterations to get more detailed and accurate simulation results (Lacy et al. 2015). This research used 500 iterations for all tested scenarios.

Generally, the simulation time uses 100 or 200 years, although less than 100 years still relevant to use. A longer simulation time is recommended for long-lived species because the final extinction may not occur until the end of the simulation time (Lacy et al. 2015). In this research, the simulation time was 100 years. The duration of time each year was 365 calendar day units. Extinction is defined as one sex left of Lesser Sulphur Crested Cockatoo. The data of the total population was a single population (one population).

\section{Inbreeding pressures, disaster, environmental concordance of reproduction and survival}

Inbreeding pressure in Yellow-crested cockatoo species has not been studied before. Thus, this research used the default Vortex value of 6.29 with $50 \%$ lethal alleles. The environmental concordance of reproduction and survival is the annual variation of reproduction probability and survival rate that is generated from random variations in environmental conditions (Lacy et al. 2015). In the simulation, this option was used considering that a good year for reproduction and a good year for survival.

The disaster impact was included as a parameter in this simulation. The extreme disaster that has occurred on Pasoso Island was a tsunami disaster, although the chances of a tsunami can only be predicted. However, this option was still chosen to see the impact of a tsunami hit again. The Yellow-crested cockatoo is a long-lived bird species, so there is a high chance of being affected by the tsunami in the future.

\section{Reproductive system}

Generally, the input for the reproduction system in VORTEX consists of four variables, i.e.: (i) Mating system: The Yellow-crested cockatoo mating system is long-term monogamy. This mating system is common among true parrot bird species. The two other species of true parrot birds' species are well known as long-term monogamous systems (Heinsohn et al. 2009; Valle 2015). (ii) Female and male reproductive age: The growth stage of The Yellow-crested cockatoo from the juvenile to the adult phase relatively takes a longer time. The process of parental care is 8 to 10 weeks (Nandika and Agustina 2018). After the bird can fly, follow the parent and mingle with their social group, it takes a long time to get a mate. The time is approximately a year. Since the breeding age is added to the period of mingling and looking for a mate, it is assumed that the ideal breeding age of The Yellow-crested cockatoo is approximately two years old. VORTEX defines breeding time as when the first child is born, not the age of sexual maturity or the age of the first conception (Lacy et al. 2015). (iii) The maximum age for reproducing in males and females: The maximum age of The Yellow-crested cockatoo is 39.97 years (Young et al. 2012). In their natural habitat, The Yellow-crested cockatoo is estimated to be able to survive until 40 years. It is difficult for older to breed. Thus, it is assumed that the Yellow-crested cockatoo does not reproduce throughout adulthood until death. The maximum reproductive age of male and Yellow-crested cockatoo in this simulation was assumed to be 35 years old.

\section{Mortality rate, mate monopolization and initial population}

The mortality rate is based on the population data calculations from 1996-2019 (Mallo et al. 2000; Nandika et al. 2012; Sandy 2015). The mortality rate for age class $0-1$, $1-2,>2$ are $83 \% ; 81 \%$, and $48 \%$, respectively. The mating system of Yellow-crested cockatoo is long-term monogamy 
(Heinsohn et al. 2009) with a sex ratio of 50\%. It is assumed that each individual gets a partner at each breeding period. Furthermore, it is assumed that $100 \%$ of males are active in mating. The initial population was determined based on the results of research in the field. The results of this study found 3 individual Yellow-crested cockatoo.

\section{Scenarios for determination analysis of minimum sustainable population size}

The scenarios in this research were various alternatives for population growth with certain input combinations that describe various conditions in the future. There were five population growth scenarios used in the analysis to determine the minimum sustainable population size. The scenarios are written below: (i) Scenario 1: Scenario 1 was a description of the current population condition. Field data shows the current population is 3 individuals. The mortality rate for age class $0-1,1-2,>2$ were $83 \%$; $81 \%$, and $48 \%$, respectively. The mortality rate was based on the average annual mortality rate from 1996-2019 (Mallo et al. 2000; Nandika et al. 2012; Sandy 2015). (ii) Scenario 2: The difference between scenario 2 and scenario 1 was the mortality rate. Scenario 2 mortality rate was reduced to half of the mortality rate in scenario 1 . The mortality rate for every class in scenario 2 was $40 \%, 40 \%$, and $24 \%$, respectively. (iii) Scenario 3: Scenario 3 was developed based on the assumption that the population management of Yellow-crested cockatoo had succeeded in reducing the mortality rate for age class $0-1$ by $20 \%$, age class $1-2$ by $20 \%$ and age class $>2$ by $15 \%$. (iv) Scenario 4 : In 2018, it was found that 7 confiscated individuals of Yellow-crested cockatoo in the BKSDA Sulawesi Tengah. These individuals were 3 females and 4 males. Scenario 4 simulated that the chance of extinction if six individuals from the seven confiscated individuals were released back into their habitat and rejoined with their rest population on Pasoso Island. The mortality rate was the same as in scenario 3. (v) Scenario 4.1: Scenario 4.1 was similar to scenario 4 by including all input parameters, but the inbreeding pressure parameter was omitted.

\section{Data analysis}

The current population size was analyzed based on population data that was collected in the field by analyzing the entire number of individuals found in all observation transects. The analysis was carried out to determine the actual number of Yellow-crested cockatoo on Pasoso
Island. The analysis was performed by reducing the number of individual birds that were counted simultaneously by different research teams.

The Population Viability Analysis (PVA) or the minimum sustainable population size was conducted referring to the five scenarios with the input parameters as mentioned above. The analysis was performed using the VORTEX ver10.0.07. 0 computer program (Lacy et al. 2015).

\section{RESULTS AND DISCUSSION}

\section{Status of population}

Based on the research results, individual Yellow-crested cockatoo was observed 59 times. At the observation time, three individual birds were encountered together 11 times, two individuals were encountered together 10 times and one individual was encountered 38 times (Table 1). The data analysis results from each team showed that several individual encounters of birds with the observer team were the same individuals. Those birds had been recorded on other observer teams on different transects. Thus, it is known that the yellow-crested cockatoo on Pasoso Island only consists of 3 individuals. The three individuals consist of two adult individuals and one young individual. It is suspected that two adults are the parents of the young one. This population has decreased sharply compared to the population in 2000 as many as 7-15 individuals (Mallo et al. 2000).

Based on these conditions, the young adult individual has little chance of getting a partner and they will not produce offspring. In the next generation, the chances of inbreeding will increase considering that all the offspring that are born come from the same parent. The opportunity of inbreeding will also increase. According to Indrawan et al. (2007), inbreeding is usually characterized by a high mortality rate. Inbreeding will produce a lower number of individuals in the next generation which the impact of inbreeding will increase to the next generation.

\section{Sustainable population size}

Based on the simulation results from all scenarios, scenario 1, 2, 3 and 4 showed a negative population growth rate with a final population of 0 . While scenario 4.1 showed a positive growth rate with a final population of 100 individuals (Table 2).

Table 1. The number of Yellow-crested cockatoos observed on each transect at each observation

\begin{tabular}{|c|c|c|c|c|c|c|c|c|c|c|c|c|c|c|c|c|c|c|}
\hline \multirow{2}{*}{ Transect } & \multicolumn{18}{|c|}{ Number of birds in each observation } \\
\hline & 1 & 2 & 3 & 4 & 5 & 6 & 7 & 8 & 9 & 10 & 11 & 12 & 13 & 14 & 15 & 16 & 17 & 18 \\
\hline Transect 1 & 0 & 0 & 0 & 1 & 1 & 0 & 0 & 0 & 0 & 0 & 1 & 1 & 1 & 0 & 0 & 0 & 0 & 1 \\
\hline Transect 2 & 1 & 1 & 0 & 0 & 1 & 1 & 0 & 1 & 0 & 1 & 1 & 0 & 0 & 1 & 0 & 1 & 1 & 1 \\
\hline Transect 3 & 1 & 1 & 3 & 2 & 3 & 2 & 3 & 2 & 3 & 3 & 2 & 3 & 2 & 2 & 3 & 1 & 2 & 3 \\
\hline Transect 4 & 1 & 1 & 1 & 1 & 1 & 0 & 2 & 3 & 1 & 1 & 0 & 0 & 1 & 0 & 2 & 3 & 3 & 2 \\
\hline Transect 5 & 0 & 0 & 1 & 1 & 1 & 1 & 0 & 0 & 0 & 1 & 0 & 1 & 0 & 0 & 1 & 1 & 1 & 1 \\
\hline
\end{tabular}


Table 2. Growth rates and final population under various growth scenarios of Yellow-crested cockatoo population

\begin{tabular}{|c|c|c|c|c|c|c|c|}
\hline \multicolumn{6}{|c|}{ Scenario } & \multicolumn{2}{|c|}{ Output scenario } \\
\hline \multirow{2}{*}{ Scenario } & \multirow{2}{*}{ Population } & \multicolumn{3}{|c|}{ Mortality rate (\%) } & \multirow{2}{*}{ Inbreeding } & \multirow{2}{*}{$\begin{array}{l}\text { Population } \\
\text { growth rate }\end{array}$} & \multirow{2}{*}{$\begin{array}{c}\text { Final } \\
\text { population }\end{array}$} \\
\hline & & Chic (0-1) & Juvenile (1-2) & Adult (>2) & & & \\
\hline 1 & 3 & 83 & 81 & 48 & 6,29 & $-0,189$ & 0 \\
\hline 2 & 3 & 40 & 40 & 24 & 6,29 & $-0,028$ & 0 \\
\hline 3 & 3 & 20 & 20 & 15 & 6,29 & $-0,0068$ & 0 \\
\hline 4 & 8 & 20 & 20 & 15 & 6,29 & $-0,0416$ & 0 \\
\hline 4.1 & 8 & 20 & 20 & 15 & 0 & 0,1618 & 100 \\
\hline
\end{tabular}

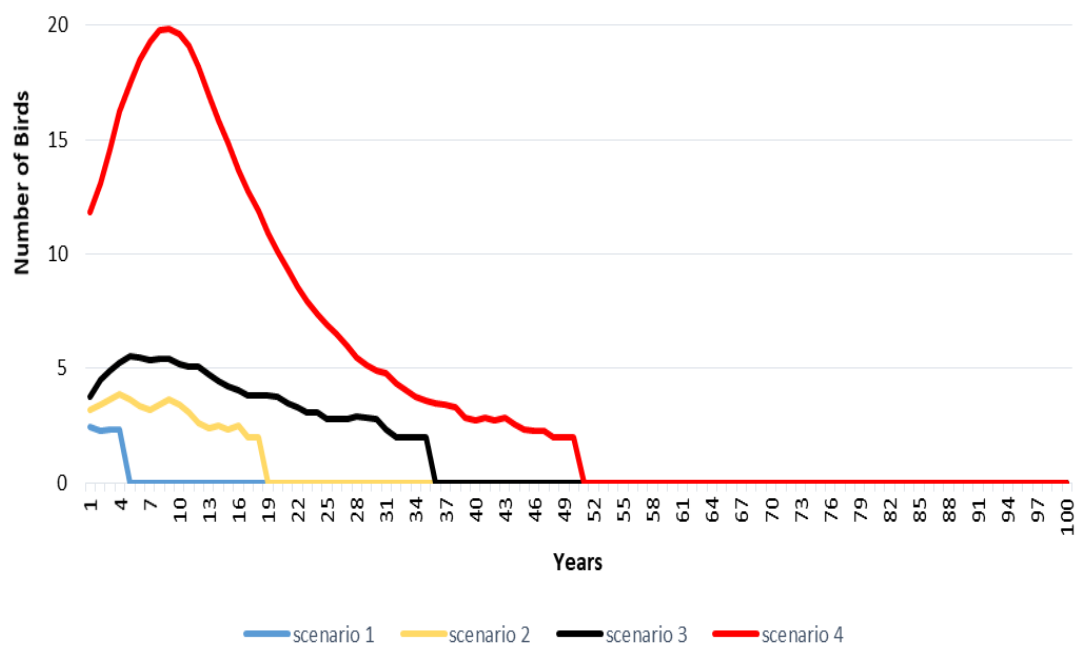

Figure 2. The growth prediction of the individual population of the Yellow-crested cockatoo on Pasoso Island based on 4 scenarios

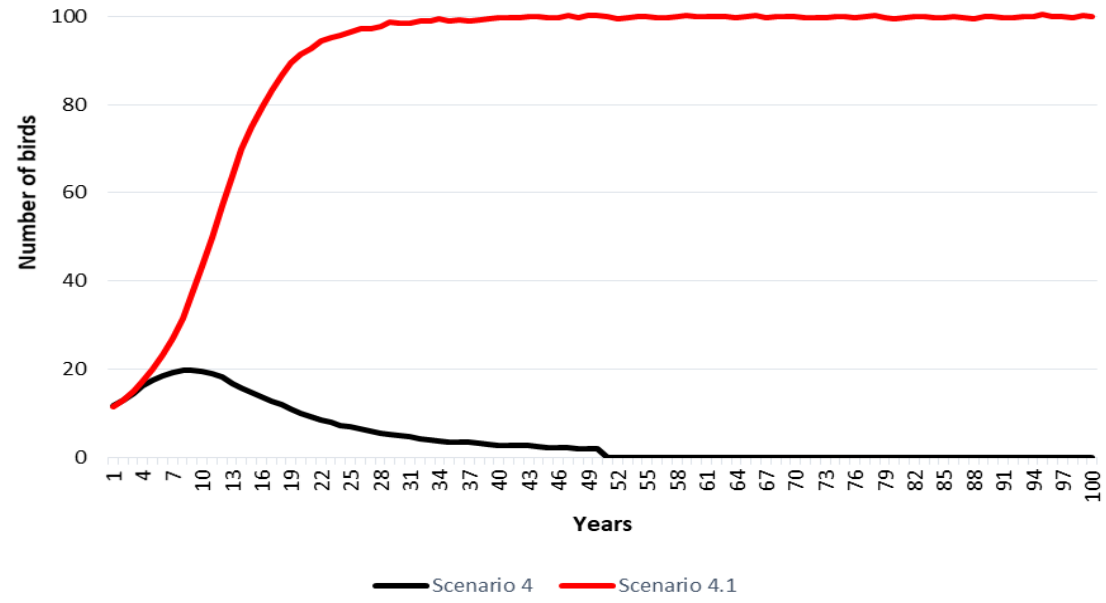

Figure 3. Population prediction of the Yellow-crested cockatoo in Pasoso Island according to two scenarios

From all simulated scenarios, there were different results about the extinction time of the Yellow-crested Cockatoo (Figure 2). The analysis of scenario 1, the current condition in Pasoso Island, showed that the bird population has a very high probability of extinction. The extinction time is a relatively short period over the next five years. The population increase in the first year then decrease in the second year and begin to become extinct in the fourth year.

The results of all simulated scenarios show that the Yellow-crested cockatoo still has a probability of extinction over 50 years. Thus, management interventions and effective management strategies are needed to reduce the extinction rate of this bird (Figure 2). Based on PVA results, it is understood that management interventions may have a significant impact on reducing the extinction rate of the Yellow-crested cockatoo. Based on scenario 2, the existing population will survive if the mortality rate is reduced to half. The current mortality rate is $80 \%$ and the reduced mortality rate is $40 \%$. This mortality reduction slows the rate of Yellow-crested cockatoo extinction until the $18^{\text {th }}$ year. 
The mortality rate reduction greatly affects the sustainability of the Yellow-crested cockatoo. Scenario 3 result show that reduces the mortality rate by $20 \%$ in the same population can be maintained until it reaches the $36^{\text {th }}$ year. Scenario 4 that combines the same condition as in scenario 3 and adds 3 pairs of new individuals can maintain the population of yellow-crested cockatoos on Pasoso Island until the $50^{\text {th }}$ year.

Based on these analysis results, although efforts to reduce the mortality rate have a significant impact on reducing the mortality rate, this is not enough. The remaining population will extinct and cannot survive until it reaches 100 years. Hence, it is necessary to do other efforts besides reducing the mortality rate. In scenario 4.1, the inbreeding pressure is eliminated. The simulation results clearly show that removing the inbreeding pressure has a significant effect on population growth. The population of Yellow-crested cockatoo will survive over 100 years with a final population of 100 individuals or at the maximum carrying capacity (Figure 3 ).

Based on this result, the best scenario to conserve Yellow-crested cockatoo was scenario 4.1. To achieve the best scenario, it is necessary to reduce the mortality rate due to predation. To increase the new population, we need including, at least three pairs, of new Yellow-crested cockatoo. The addition of a new population to increasing the existing population can also increase the genetic diversity of these bird population on Pasoso Island. Based on the result, it is known that the minimum size for a sustainable population of Yellow-crested cockatoo on Pasoso Island is four pairs ( 8 birds). The source of the population of the added yellow-crested cockatoo came from confiscations in BKSDA Central Sulawesi. This number is the minimum required to maintain the Yellowcrested cockatoo population on Pasoso Island.

\section{The determining factor for the sustainability of the Lesser Sulphur Crested Cockatoo}

Scenario 4.1 showed that inbreeding and predation factors were the determining factors for the sustainability of the Yellow-crested cockatoo population on Pasoso Island. The inbreeding factor was expected to be the main factor that affects the high rates of mortality for chicks and adults. Another threat in this research was predation. The high potential threat of predation in birds can be seen in $\mathrm{Fu}$ et al. (2016) that showed a variety of nest predators can cause bird (Liocichla omeiensis) nesting failure. Mallo et al. (2000) reported that the slender-billed crow (Corvus enca) was a predator of eggs. The spotted kestrel (Falco moluccensis) is the predator of the juvenile Yellow-crested cockatoo on Pasoso Island. On the other hand, at the time of observation, reticulated pythons (Python reticulatus) and monitor lizards (Varanus salvator) were also found. These species are also strongly suspected to have the potential to become predators although there have been no reports stating about that. This assumption is substantiated by the results of another study on Masalembo Island that monitor lizards are predators of Cacatua sulphurea abboti eggs and chicks (Nandika 2020). In another research stated that pythons are egg predators of The palm cockatoo (Probosciger aterrimus) in Papua New Guinea and Australia (Heinsohn et al. 2009).

The combination of inbreeding and predation factors is the cause of the high mortality rate of Yellow-crested cockatoo on Pasoso Island. Inbreeding has the potential to reduce population growth rates and increase the risk of extinction (Keller et al. 2012). It also can reduce viability and reproduction (Waller and Keller 2020). With a mortality rate above $50 \%$ in the $0-2$ year age class, the population growth of the Yellow-crested cockatoo is very low. Its small population size and low population growth rate make this species vulnerable to any threat or change. It means that this population is not stable in conservation. The reason is to protect most species require a large population. When the size of a population decreases, it is vulnerable to become extinct.

Based on the Yellow-crested cockatoo population preservation determinant factors, the management steps to ensure population sustainability are mating management to prevent inbreeding and control of predatory animals on Pasoso Island. According to Roos et al. (2018), both elimination and control of predators are effective strategies for the conservation of vulnerable bird populations. Besides, to increase the population size, at least 8 individuals or 4 pairs of adult individuals from the current population status of 3 individuals, alternative steps that can be taken are a program of release or population restoration (restocking) to their natural habitat on Pasoso Island. We can utilize confiscated and captive birds from captivity or conservation institutions. It has been carried out on Bali myna (Leucopsar rotschildi). Release activity is one way that aims to improve, restore or strengthen endangered population conditions (Masy'ud and Ginoga 2016).

Release activation must be preceded by predator control. According to White et al. (2012), predation is the most important factor of several factors that determine the release activity of bird species from the Psittacidae family. A high predation threat can reduce the success and survival rates of birds after release activity. Other studies have also reported that predators are a major factor determining the successful release of birds (Jones and Merton 2012), mammals and reptiles (Moseby et al. 2011).

In conclusion, the population of Yellow-crested cockatoo on Pasoso Island is only 3 individuals which are two adults and one young individual. It is suspected that two adult individuals are the parents of young individuals. From the simulation, scenario 4.1 is the best scenario to maintain the population of the Yellow-crested cockatoo. The scenario is a sustainable minimum population with four pairs ( 8 individuals) to maintain the preservation of this Yellow-crested cockatoo population on Pasoso Island. The determinants of population sustainability in scenario 4.1 are inbreeding and predation factors. It is necessary to control the mating management and predators by both humans and carnivores. The alternative to achieve this minimum sustainable population size ( 8 individuals or 4 pairs of broodstock) is a release or restocking program using confiscated birds or captive birds. 


\section{ACKNOWLEDGEMENTS}

We would like to thank the Lembaga Pengelola Dana Pendidikan (LPDP) of the Indonesian Ministry of Finance which funded doctoral studies at the Bogor Agricultural University, Indonesia and funded this research. We also thank the BKSDA Sulawesi Tengah for providing permits and supporting information.

\section{REFERENCES}

Akçakaya HR, Sjögren-Gulve P. 2000. Population viability analysis in conservation planning: An overview. Ecol Bull 48: 9-21.

BirdLife International. 2021. Species factsheet: Cacatua sulphurea. http://www.birdlife.org

BKSDA (Natural Resources Conservation Agency). 2014. Monitoring of Yellow-crested cockatoo at the Pasoso Island Wildlife Reserve. Central Sulawesi BKSDA, Palu. [Indonesian]

Chaudhary V, Oli MK. 2019. A critical appraisal of population viability analysis. Conserv Biol 34 (1): 26-40. DOI: 10.1111/cobi.13414.

CITES (Convertion On International Trade In Endangered Spesies of Wild Fauna and Flora). 2021. Appendices I, II and III. www.cites.org.

Fu Y, Chen B, Dowell SD, Zhang Z. 2016. Nest predators, nest-site selection and nest success of the Emei Shan Liocichla (Liocichla omeiensis), a vulnerable babbler endemic to Southwestern China. Avian Res 7 (18): 1-6. DOI: 10.1186/s40657-016-0054-1.

Haskins KE. 2015. Alternative perspectives on reintroduction success. Anim Conserv 18: 409-410. DOI: 10.1111/acv.12241.

Heinsohn R, Zeriga T, Murphy S, Igag P, Legge S, Mack AL. 2009. Do Palm cockatoos (Probosciger aterrimus) have long enough lifespans to support their low reproductive success?. Emu 109: 183-191. DOI: 10.1071/MU08053.

Indrawan M, Primack RB, Supriatna J. 2007. Conservation Biology, Revised Edition. Obor Foundation, Jakarta. [Indonesian]

Jones CG, Merton DV. 2012. A tale of two islands: The rescue and recovery of endemic birds in New Zealand and Mauritius. In: Ewen JG, Armstrong DP, Parker KA, Seddon PJ (eds). Reintroduction Biology: Integrating Science and Management. Wiley-Blackwell, London. DOI: 10.1002/9781444355833.ch2.

Keller LF, Biebach I, Ewing SR, Paquita EA, Hoeck. 2012. The genetics of reintroductions: Inbreeding and genetic drift. In: Ewen JG, Armstrong DP, Parker KA, Seddon PJ (eds). Reintroduction Biology: Integrating Science and Management. Wiley-Blackwell, London. DOI: $10.1002 / 9781444355833 . c h 11$.

Lacy RC, Miller PS, Traylor K-Holzer. 2015. Vortex 10 User's Manual. 19 January 2015 update. IUCN SSC Conservation Breeding Specialist Group, and Chicago Zoological Society, Minnesota.

Mallo FN, Alam S, Harjun, Mamengko C. 2000. Status of Yellow-crested cockatoo (Cacatua sulphurea sulphurea) in SM on Pasoso Island, Central Sulawesi. Palu BQD Foundation and Birdlife InternationalIndonesia Program, Bogor. [Indonesian]

Masy'ud B, Ginogah LN. 2016. Wildlife Breeding. IPB Press, Bogor [Indonesian]
Morrison C, Wardle C, Castley JG. 2016. Repeatability and reproducibility of population viability analysis (PVA) and the implications for threatened species management. Front Ecol Evol 4: (98): 1-7. DOI: 10.3389/fevo.2016.00098.

Moseby KE, Read JL, Paton DC, Copley P, Hill BM, Crisp HA. 2011. Predation determines the outcome of 10 reintroduction attempts in arid South Australia. Biol Conserv 144: 2863-2872. DOI: 10.1016/j.biocon.2011.08.003

Nandika D. 2020. Ecology of the Yellow-crested cockatoo Cacatua sulphurea abboti in Masakambing, Masalembu Islands, East Java. [Thesis]. Bogor Agricultural Institute, Bogor. [Indonesian]

Nandika D, Agustina D. 2018. Ecology of Lesser Sulphur Creasted Cockatoo Cacatua sulphurea sulphurea at Rawa Aopa Watumohai National Park, Southeast Sulawesi. Metamorfosa 5(2): 177-188. DOI: 10.24843/metamorfosa.2018.v05.i02.p07.

Nandika D, Agustina D, Halouate M. 2012. Study of population and conservation Lesser sulphur-crested cockatoo Cacatua sulphurea at Pasoso Island, Central Sulawesi, Komodo National Park, and Sumba, East Nusa Tenggara. World Parrot Trust. https://issuu.com/worldparrottrust/docs/yellowcrested_cockatoo_report_may_2012.

Pe'er G, Matsinos YG, Johst K, Franz KW, Turlure C, Radchuk V, Malinowska AH, Curtis JMR, Lewis IN, Wintle BA, Henle K. 2013. A protocol for better design, application, and communication of population viability analyses. Conserv Biol 27: 644-656. DOI: 10.1111/cobi.12076.

Roos S, Smart J, Gibbons DW, Jeremy D, Wilson JD. 2018. A review of predation as a limiting factor for bird populations in mesopredatorrich landscapes: A case study of the UK. Biol Rev 000-000. DOI:10.1111/brv.12426.

Sandy 2015. Population and Habitat of Yellow-crested Cockatoo (Cacatua sulphurea) in Primary Forest in Pasoso Island Wildlife Reserve, Balaesang Tanjung District, Donggala Regency. [Undergraduated Thesis]. Tadulako University, Palu. [Indonesian]

Skarpaas O, Stabbetorp OE. 2011. Population viability analysis with species occurrence data from museum collections. Conserv Biol 25(3): 577-586. DOI: 10.1111/j.1523-1739.2010.01636.x.

Valle S. 2015. Population Viability and Conservation of Grey Parrots Psittacus erithacus on the Island of Príncipe, Gulf of Guinea. [Dissertation]. Manchester Metropolitan University, Manchester.

Waller DM, Keller LF. 2020. Inbreeding and inbreeding depression. Trends Ecol Evol 17(5): 230-241. DOI:10.1016/S01695347(02)02489-8. DOI: 10.1016/S0169-5347(02)02489-8.

White Jr TH, Collar NJ, Moorhouse RJ, Sanz V, Stolen ED, Brightsmith DJ. 2012. Psittacine reintroductions: Common denominators of success. Biol Conserv 148: 106-115. DOI: 10.1016/j.biocon.2012.01.044

Young AM, Hobson EA, Lackey LB, Wright TF. 2012. Survival on the ark: Life-history trends in captive parrots. Anim Conserv 15: 28-43. DOI: 10.1111/j.1469-1795.2011.00477.x.

Zeigler SR, Castaldo JPC, Neel MC. 2013. Actual and potential use of population viability analyses in recovery of plant species listed under the U.S. endangered species act. Conserv Biol 27(6): 1265-1278. DOI: $10.1111 /$ cobi.12130.

Zhang Y, Zheng G. 2007. A population viability analysis (PVA) for cabot's tragopan (Tragopan caboti) in Wuyanling, South-east China. Bird Conserv Int 17: 151-161. DOI: 10.1017/S0959270907000652. 